REMOA (Revista Eletrônica do Curso de Especialização em Educação Ambiental da UFSM)

\title{
PROJETO SORRIR FAZ BEM: O VOLUNTARIADO NA VIDA ACADÊMICA
}

\author{
Lauren Oliveira Lima Bohner ${ }^{1}$, Luiz Jarbas Godoy Filho ${ }^{1}$, Graziela de Luca Canto ${ }^{2}$, \\ ${ }^{1}$ Acadêmic(o)a do Curso de Odontologia (UFSC). \\ laurenamp@hotmail.com \\ ${ }^{2}$ Professora e Coordenadora do curso de graduação em Odontologia (UFSC) \\ delucacanto@gmail.com
}

\section{RESUMO}

A Casa Lar Emaús é uma entidade privada, filantrópica e sem fins lucrativos que acolhe meninos de 6 aos 18 anos em situação de risco. A esses meninos é oferecida moradia, alimentação, reforço escolar, educação não formal, atividades esportivas, encaminhamento médico, e outras ações que visem desenvolvimento integral da criança. Todas as pessoas ligadas à instituição dedicam seu tempo voluntariamente. Para integrar os universitários no mundo do voluntariado, aproximandoos da comunidade em que vivem, o Grupo PET ODONTO-FONO realiza o Projeto Sorrir Faz Bem, no qual são desenvolvidas atividades voluntárias de reforço escolar na Casa Lar Emaús. Além de auxiliar nas tarefas de casa, os estudantes universitários apresentam aos jovens o prazer do estudo, contribuindo no resgate da sua auto-estima. Por sua vez, o projeto é uma experiência enriquecedora para o estudante universitário, já que proporciona crescimento pessoal e fortalecimento de sua cidadania.

Palavras - chave: Voluntariado, projeto de extensão.

\begin{abstract}
Emaus ' house it is a private entity, philanthropyc and noneconomic purposes, that protects 6 to 18 year old boys, in a risk situation. To those boys it is offered a house, food, school help, non-formal education, sports, cares of health and actions that leads to the child integral development. All the persons who are connect to the Instituition dedicates their time voluntarily. To integrate the academics to the Volunteer World, connecting them to the Community that they live, the PET Odonto - Fono Group makes the "Sorrir Faz Bem" Project, where they developed volunteer activities with school help in Emaus' house. Besides providing homework help, the academic students shows the young boys the pleasure of studying, contributing with the self esteem rescue. On the other hand, this project it is a rich experience to the student, since it proposes the personal development, and fortification of their citizenship.
\end{abstract}

Keywords: Volunteering, extension project. 


\section{Monografias Ambientais}

REMOA (Revista Eletrônica do Curso de Especialização em Educação Ambiental da UFSM)

\section{INTRODUÇÃO}

O trabalho voluntário é uma atividade em que a pessoa doa o seu tempo para beneficiar o próximo, sem retribuição monetária (FERREIRA et al., 2008), contribuindo com a comunidade e se tornando um cidadão consciente e competente em relação à sua vida profissional (SBERGA, 2011). É considerado trabalho voluntário qualquer prestação de serviço realizada na busca da resolubilidade de problemas sociais, sem envolver remuneração econômica. Pode ser um trabalho formal, onde as ações são voltadas a organizações, ou um trabalho informal, considerada qualquer ajuda ao próximo (DE SOUZA \& LAUTERT, 2008).

O trabalho voluntário é uma alternativa para os jovens que sonham por um mundo justo e igualitário, e idealizam projetos buscando o bem - estar social (SBERGA, 2011). A inserção dos jovens nos problemas comunitários cria condições para a aquisição de uma melhor compreensão da realidade e participação nas relações sociais que propiciem o exercício da cidadania (CASTILHO \& CASTILHO, 2011).

A Universidade é um local onde a aquisição de conhecimentos permite a formação de conceitos, construção de autonomia e formação dos alunos como cidadãos conscientes (CASTILHO \& CASTILHO, 2011). A realização de Projetos Sociais dentro do campo universitário integra a promoção da interdisciplinariedade, a democratização do conhecimento acadêmico e a formação de uma visão integrada do social (SARAIVA, 2007). A participação do estudante universitário na realização de trabalhos voluntários contribui para a formação de profissionais aptos a lidar com os desafios da sociedade, além de estimular o crescimento pessoal e a capacidade de autocrítica (SBERGA, 2011).

O acadêmico, como voluntário, tem a função de colaborar nos serviços humanitários e educacionais, assim como na transformação das políticas sociais (SBERGA, 2011). Ações direcionadas a pessoas necessitadas demonstram a solidariedade do voluntariado, e a doação de seu tempo livre, demonstra gratuidade (DE SOUZA \& LAUTERT, 2008). O voluntariado ocorre com pessoas que necessitam de atenção especial, como crianças e adolescentes em situações de risco.

São consideradas situações de risco os eventos negativos que ocorrem durante a vida, onde a criança possa vir a apresentar problemas físicos, sociais ou emocionais. Esses fatores se tornarão prejudiciais ao desenvolvimento de uma pessoa, dependendo de qual vulnerável esta se encontra (BARDAGI et al., 2005).

A violência social é um fator de risco considerado como um grave problema mundial, que prejudica crianças e adolescentes durante um período de desenvolvimento. É conceituada como a ação ou omissão que ocasionam danos físicos, morais e emocionais ao outro. O tipo mais frequente é a violência doméstica, e ocorre, muitas vezes, dentro do convívio familiar. Também considera-se maus-tratos ações de negligência ou abandono, caracterizada pelo não atendimento das necessidades físicas e emocionais da criança; abuso sexual, onde a vítima é exposta a estímulos sexuais impróprios para a idade; e abuso psicológico, considerada a rejeição da criança (PIRES, 2005). 


\section{Monografias Ambientais}

REMOA (Revista Eletrônica do Curso de Especialização em Educação Ambiental da UFSM)

A criança ou adolescente, quando submetida a situações de maus-tratos, costuma apresentar baixo nível de motivação vital, autoconceito negativo, baixa auto-estima e perspectivas de futuro pouco desenvolvidas (BARDAGI et al., 2005). Além disso, futuramente, tendem a se tornar agressivas, fazer uso de drogas e ter comportamento abusivo (PIRES, 2005).

A atenção a essas crianças pode ser dada voluntariamente na forma de Projetos Sociais, através de recursos que as auxiliem a superar os problemas, descobrir suas necessidades e assumir compromissos, para que se tornem adultos independentes. Promover a saúde e o desenvolvimento é a melhor forma de intervenção. Ainda, o trabalho realizado com esse grupo promove a interação positiva entre o voluntário e a criança, ajudando a aliviar os sentimentos de isolamento e a inadequação de uma criança vítima de violência social (Ministério da Saúde).

Quanto ao desenvolvimento pedagógico, as vítimas de maus-tratos costumam apresentar dificuldade de aprendizado e baixo rendimento escolar (Ministério da Saúde). Além disso, crianças e adolescentes em situações ditas de risco geralmente possuem oportunidades restritas à uma boa educação, e raramente são criadas com a preocupação da escolha de um nível superior. (BARDAGI et al., 2005). Assim, a atenção a este tipo de criança requer programas de estimulação da linguagem oral e escrita para suprir seu déficit cognitivo e melhorar seu desempenho acadêmico (Ministério da Saúde). A atitude promove também ações a longo prazo, já que auxilia na descoberta do desempenho vocacional, processo fundamental na construção da identidade e na projeção de uma imagem futura do adulto que a criança gostaria de ser (BARDAGI et al., 2005).

A Casa Lar Emaús, localizada em Florianópolis, Santa Catarina, é uma entidade filantrópica privada, e sem fins lucrativos que acolhe meninos de 6 a 18 anos afastados da família pelo Conselho Tutelar, quando esses sujeitos são abandonados ou sofrem maus-tratos dentro de casa. Os meninos recebem moradia, alimentação, reforço escolar, educação não formal, atividades esportivas, encaminhamento médico, e outras ações que visam desenvolvimento integral da criança. Atualmente a Casa Lar abriga oito crianças, e a grande maioria das pessoas ligadas à instituição dedica seu tempo de forma voluntária (Casa Lar).

Para integrar os acadêmicos ao mundo do voluntariado, aproximando-os da comunidade em que vivem, o Grupo PET ODONTO-FONO, da Universidade Federal de Santa Catarina, realiza o Projeto de Extensão "SORRIR FAZ BEM", no qual são desenvolvidas atividades voluntárias de reforço escolar na Casa Lar Emaús. O projeto tem como objetivo apresentar aos jovens o prazer do estudo, desenvolvendo suas habilidades individuais e contribuindo no resgate da sua autoestima.

\section{METODOLOGIA}

O projeto é realizado em Florianópolis, Santa Catarina, por estudantes universitários dos cursos de Odontologia e Fonoaudiologia da Universidade Federal de Santa Catarina. A populaçãoalvo abrange jovens na faixa etária de 6 à 18 anos, vítimas de maus-tratos e residentes da Casa Lar Emaús. 


\section{Monografias Ambientais}

REMOA (Revista Eletrônica do Curso de Especialização em Educação Ambiental da UFSM)

Estudantes universitários participantes do Grupo PET Odonto - Fono, realizam visitas semanais à Casa Lar. Durante o período de uma hora e meia, cada acadêmico é responsável por uma criança ou adolescente, auxiliando o jovem na realização da tarefa escolar, e incentivando o estudo através de exercícios e brincadeiras. Atividades lúdicas são realizadas, voltadas para o desenvolvimento do raciocínio e destreza manual, de acordo com a potencialidade de cada criança. Palavras de incentivo procuram dar ao jovem um estímulo para o resgate de sua autoestima.

\section{RESULTADOS}

Com o programa "Sorrir Faz Bem", o jovem residente na Casa Lar é estimulado a realizar suas tarefas escolares e construir o prazer do estudo. As crianças são acompanhadas, diagnosticase suas dificuldades, e a partir daí o estudante universitário busca superá-las, através de exercícios e atividades específicas.

Reforços positivos por parte do estudante universitário ajudam o jovem a superar as dificuldades, recuperando a confiança em suas capacidades. Além disso, a relação de afeto criada no grupo alivia os sentimentos de isolamento ou inadequação da criança e adolescente.

O trabalho voluntário não é benéfico apenas para quem o recebe, mas também para quem o realiza. O estudante universitário, ao participar de projetos sociais, tem a oportunidade de vivenciar diferentes realidades. Experiências de solidariedade propiciam o amadurecimento do indivíduo, resultando em uma formação acadêmica compromissada com as necessidades sociais .

\section{DISCUSSÃO}

Os jovens residentes na Casa Lar foram afastados de sua família por vivenciar situações de maus-tratos. Segundo Bardagi et al. (2005), crianças ou adolescentes submetidos a situações de maus-tratos apresentam déficit intelectual, sendo necessário programas de estimulação oral e escrita para melhorar seu desempenho acadêmico. O projeto visa, primeiramente, ajudar as crianças e adolescentes a superar suas dificuldades no estudo. Segundo o Ministério da Saúde, agindo positivamente, é possível reverter as condições adversas que pesam sobre a vida dessas pessoas ainda em formação.

Além disso, jovens que passaram por situações negativas durante a vida costumam apresentar problemas psicológicos, como baixa auto-estima e dificuldade de relacionamento pessoal (PIRES et al., 2005). A relação afetiva criada entre as crianças e os universitários promove um sentimento de afeto e companheirismo, contribuindo para o desenvolvimento de sentimentos prazerosos.

Crianças que vivem em situações de risco, em geral, não são educados com a preocupação de um curso em nível superior (BARDAGI et al., 2005). O processo de formação profissional inicia na adolescência, onde são elaboradas expectativas futuras a partir das trajetórias vivenciadas pelo 


\section{Monografias Ambientais}

REMOA (Revista Eletrônica do Curso de Especialização em Educação Ambiental da UFSM)

indivíduo. A escolha da profissão envolve a realidade familiar, sócio-econômica e sócio-cultural do indivíduo. Além de meio de subsistência, o trabalho envolve fontes de prazer e realização de potencialidades individuais (BARDAGI et al., 2005). O incentivo aos estudos busca, a longo prazo, auxiliar na orientação profissional dos jovens, através da construção da identidade do indivíduo.

Segundo Sberga (2011), o trabalho voluntariado não só fortalece o sentimento de cidadania, mas também ajuda o jovem voluntário a conhecer a si mesmo e descobrir suas potencialidades. Visando a formação de profissionais preparados a encarar a desafios, o Projeto "Sorrir Faz Bem" atua na vida acadêmica permitindo ao estudante universitário uma maior compreensão de diferentes realidades sócio-econômicas, culturais e sociais.

\section{CONCLUSÃO}

A inserção da Universidade nos problemas comunitários permite ao estudante uma melhor compreensão da realidade, proporcionando o exercício da cidadania e resultando na formação de profissionais aptos a lidar com os desafios sociais.

O trabalho realizado na Casa Lar permite que os estudantes universitários apresentem aos jovens o prazer do estudo, superando suas dificuldades de aprendizado e melhorando seu rendimento acadêmico. Além disso, constrói-se uma relação de afeto no grupo, superando os sentimentos de isolamento do indivíduo e contribuindo no resgate da sua autoestima.

\section{REFERÊNCIAS}

"Casa Lar". Disponível em http://www.casalaremaus.org.br. Acesso em 20 de maio 2011.

BARDAGI, M.P.; ARTECHE, A.X.; NEIVA-SILVA, L. "Projetos sociais com adolescentes em situação de risco: Discutindo o trabalho e a intervenção profissional como estratégias de intervenção". Violência e risco na infância e adolescência: Pesquisa e intervenção, Casa do Psicólogo, p. 101-146, 2005.

CASTILHO, M.L.R.; CASTILHO, A.L. “A Universidade e os Projetos Sociais: Projeto Rondon - Cooperação entre a universidade e comunidades do Estado do Mato Grosso/ MT". Disponível em http://www.estudosdotrabalho.org/anais6seminariodotrabalho/myrianluciaruizcastilhoeandreluizcastilho.pdf. Acesso em: 30 maio. 2011.

DE SOUZA, L.M.; LAUTERT L. "Trabalho voluntário: Uma alternativa para a promoção de saúde dos idosos” Rev. esc. enferm. USP, v.42 (2), 2008.

FERREIRA, M.; PROENCA, T.; PROENCA, J.F. “As motivações no trabalho voluntário”. Rev. Portuguesa e Brasileira de Gestão, v. 7(3), p.43-53, 2008.

MENDES, V.R. “Atividades recreativas em uma Casa Lar: contribuições à formação universitária”. Motriz, Rio Claro, 
REMOA (Revista Eletrônica do Curso de Especialização em Educação Ambiental da UFSM)

v.15(4), p.1014-1024, 2000.

Ministério da "Vaúde. faz mal ància saúde". Disponível em http://dtr2001.saude.gov.br/editora/produtos/livros/pdf/06 0315 M.pdf. Acesso em 20 de maio 2011.

PIRES, A.L.D.; MIYAZAKI, M.C.O.S. "Maus-tratos contra crianças e adolescentes: Revisão de literatura para profissionais da saúde". Arq Ciênc Saúde ,12(1), p.42-49, 2005.

SARAIVA, J.L. "Papel da Extensão Universitária na formação de estudantes e professores”. Brasília Med , 44(3), 220225, 2007.

SBERGA, A.A. "Voluntariado educativo". Disponível em http://www.educardpaschoal.org.br/web/upload/NossosLivros/72 livro volunteducativo.pdf. Acesso em 20 de maio 2011. 